\title{
Nocturnal Gastroesophageal Reflux Revisited by Impedance-pH Monitoring
}

\author{
Fernando Fornari, ${ }^{1,2 *}$ Kathleen Blondeau, ${ }^{1}$ Veerle Mertens, ${ }^{1}$ Jan Tack ${ }^{1}$ and Daniel Sifrim ${ }^{1,3}$ \\ ${ }^{1}$ Center for Gastroenterological Research, Catholic University of Leuven, Belgium, ${ }^{2}$ Faculdade de Medicina, Programa de Pós-Graduação: \\ Ciências em Gastroenterologia, Universidade Federal do Rio Grande do Sul, Porto Alegre, Brazil, ${ }^{3}$ Barts and The London School of Medicine \\ and Dentistry, Queen Mary University of London, UK
}

\section{Background/Aims}

Impedance-pH monitoring allows detailed characterization of gastroesophageal reflux and esophageal activity associated with reflux. We assessed the characteristics of nocturnal reflux and esophageal activity preceding and following reflux.

\section{Methods}

Impedance-pH tracings from 11 healthy subjects and 76 patients with gastroesophageal reflux disease off acid-suppressive therapy were analyzed. Characteristics of nocturnal supine reflux, time distribution and esophageal activity seen on impedance at 2 minute intervals preceding and following reflux were described.

\section{Results}

Patients had more nocturnal reflux events than healthy subjects (8 [4-12] vs 2 [1-5], $P=0.002)$, with lower proportion of weakly acidic reflux (57\% [35-78] vs $80 \%$ [60-100], $P=0.044$ ). Nocturnal reflux was mainly liquid $(80 \%)$ and reached the proximal esophagus more often in patients (6\% vs $0 \%, P=0.047)$. Acid reflux predominated in the first 2 hours $(66 \%)$ and weakly acidic reflux in the last 3 hours (70\%) of the night. Most nocturnal reflux was preceded by aboral flows and cleared by short lasting volume clearance. In patients, prolonged chemical clearance was associated with less esophageal activity.

\section{Conclusions}

Nocturnal weakly acidic reflux is as common as acid reflux in patients with gastroesophageal reflux disease, and predominates later in the night. Impedance-pH can predict prolonged chemical clearance after nocturnal acid reflux.

\section{(J Neurogastroenterol Motil 2011;17:148-157)}

\section{Key Words}

Esophageal pH monitoring; Gastroesophageal reflux; Sleep

Received: December 4, 2010 Revised: January 5, 2011 Accepted: January 13, 2011

(c) This is an Open Access article distributed under the terms of the Creative Commons Attribution Non-Commercial License (http://creativecommons. org/licenses/by-nc/3.0) which permits unrestricted non-commercial use, distribution, and reproduction in any medium, provided the original work is properly cited.

*Correspondence: Fernando Fornari, PhD

Programa de Pós-Graduação: Ciências em Gastroenterologia, Rua Ramiro Barcelos 2400, segundo andar, Porto Alegre-RS 90035-003, Brazil

Tel: +55-51-33085603, Fax: +55-51-33085616, E-mail: FernandoFornari@gmail.com

Financial support: This study was supported by grants from the FWO and the "Geconcerteerde Onderzoeksactie" of the University of Leuven. Conflicts of interest: None. 


\section{Introduction}

Nocturnal acid gastroesophageal reflux can induce sleep disturbances, as well as decreased health-related quality of life and increased risk of esophageal and respiratory complications. ${ }^{1-8}$ In addition, nocturnal acid reflux has been associated with more severe esophageal mucosal damage, such as peptic stricture ${ }^{9}$ and adenocarcinoma. $^{10}$

As a group, patients with gastroesophageal reflux disease (GERD) have more frequent nocturnal acid reflux than healthy controls, which is a difference that cannot be explained by abnormal sleep patterns. ${ }^{11}$ In healthy subjects, nocturnal acid reflux is very rare and occurs during transient lower esophageal sphincter relaxations (TLESRs). ${ }^{12}$ In patients with GERD, nocturnal acid reflux may occur during TLESRs but other mechanisms such as free reflux (during absent lower esophageal sphincter [LES] pressure) or straining (during low LES pressure) are considered to be more relevant, particularly in the presence of hiatal hernia. ${ }^{13}$

So far, studies assessing nocturnal reflux have focused on acid events. More recently, studies using 24 hour impedance-pH monitoring described the occurrence of nocturnal weakly acidic reflux. These studies found very low frequency of nocturnal weakly acidic reflux in healthy subjects. The prevalence of nocturnal weakly acidic reflux in GERD patients "off” proton pump inhibitor (PPI) was low compared to that of acid reflux, however, patients "on" PPI could still have significant number of nocturnal weakly acidic reflux. ${ }^{14-18}$

The mechanisms involved in the occurrence of nocturnal reflux and the subsequent clearance of the refluxate are not completely elucidated. In most reflux episodes, including those during TLESRs, previous short arousals seem to be mandatory. ${ }^{11}$ Esophageal clearance of nocturnal reflux depends mainly on primary and less so on secondary peristalsis. ${ }^{12,19}$ Recent studies using actigraphy combined with $\mathrm{pH}$ monitoring revealed that most episodes of nocturnal acid reflux occurred during recumbentawake and not the recumbent-asleep period, suggesting sleep to be suppressive of acid reflux. ${ }^{20,21}$

Previous studies have assessed the sleep pattern and esophageal activity preceding nocturnal acid reflux using esophageal manometry-pH measurements during nocturnal electroencephalogram monitoring. ${ }^{11,12}$ Clearance of acid reflux has been studied with conventional pH-metry. ${ }^{22,23}$ Esophageal impedance$\mathrm{pH}$ monitoring allows continuous assessment of nocturnal esophageal antegrade and retrograde bolus movements. In this way, it is possible to assess (1) spontaneous or swallow induced esophageal activity preceding nocturnal reflux, (2) the occurrence of reflux and its characteristics and (3) the pattern of volume and chemical clearance after nocturnal reflux.

The aim of this study was to re-assess nocturnal gastroesophageal reflux using impedance-pH monitoring focusing on (1) prevalence and characteristics of nocturnal acid and weakly acidic reflux and (2) the preceding esophageal activity and the clearance mechanism following nocturnal reflux.

\section{Materials and Methods}

\section{Subjects}

In this cross-sectional study, nocturnal reflux was assessed in 76 GERD patients and in 11 asymptomatic healthy subjects. To be included, patients and healthy subjects needed to have at least 1 nocturnal reflux episode detected during impedance-pH monitoring. Patients were studied “off” acid-suppressive therapy, at least 7 days after the drug withdrawal. They had diurnal heartburn and/or acid regurgitation as predominant symptoms, combined or not with atypical symptoms, such as chronic cough, chest pain, hoarseness and asthma. The presence of nocturnal symptoms was not a pre-requisite. Patients were classified as having normal total acid exposure, increased upright or increased bi-positional acid exposure. Increased acid exposure was defined as the percentage with $\mathrm{pH}<4,>4.2 \%$ (total), $>6.3 \%$ (upright) or $>1.2 \%$ (supine). ${ }^{24}$ Healthy volunteers denied history of heartburn and acid regurgitation.

The study was conducted according to the rules of the Helsinki declaration and was approved by the local ethical committee.

\section{Impedance-pH Monitoring}

This procedure was performed using a Sleuth ${ }^{\circledR}$ ambulatory system (Sandhill Scientific, Inc, Highland Ranch, CO, USA). The equipment includes a portable data-logger with impedance-pH amplifiers and catheters containing 2 antimony $\mathrm{pH}$ electrodes (15 cm apart) and 8 impedance electrodes (2, 4, 6, 8, $10,14,16$ and $18 \mathrm{~cm}$ from the tip of the catheter). Each pair of adjacent electrodes represents an impedance-measuring segment, $2 \mathrm{~cm}$ in length, corresponding to 1 recording channel. The impedance amplifier delivers $\mathrm{AC}$ voltage in a range of $1-2 \mathrm{kHz}$ with resulting current flow variations in response to intraluminal impedance changes. Tracings were uploaded onto a personal com- 
puter and displayed on a single screen for computer assisted manual analysis (Bioview Analysis ${ }^{\circledR}$, version 5.0.9, Sandhill Scientific, Inc).

The catheter was passed through the nose under topical anesthesia and positioned in the esophageal body to record $\mathrm{pH}$ at 5 $\mathrm{cm}$ above the manometrically determined LES, and impedance at $3,5,7,9,15$ and $17 \mathrm{~cm}$ proximal to the LES. The distal $\mathrm{pH}$ sensor was positioned in the gastric lumen, $15 \mathrm{~cm}$ below to the esophageal $\mathrm{pH}$ sensor. Subjects were encouraged to maintain normal daily activities, eat usual meals and remain upright during the day. A diary card was provided to record meal times, posture changes and symptoms.

\section{Data Analysis}

\section{Definition and characterization of nocturnal reflux}

We first analyzed some characteristics of nocturnal supine period in both GERD patients and controls, including interval between dinner and bedtime, and total duration of nocturnal supine period. We subsequently identified manually all episodes of nocturnal reflux, including the 2 minute tracings preceding and following each episode.

Nocturnal reflux was defined as any kind of reflux event detected by impedance-pH monitoring during the nocturnal supine period as referred by the patient in the diary. Gastroesophageal liquid reflux was defined as a retrograde $50 \%$ drop in impedance starting distally and propagating to at least the more proximal impedance measuring segment. Gas reflux was defined as a rapid (3 $\mathrm{k} \Omega / \mathrm{sec}$ ) increase in impedance $>5 \mathrm{k} \Omega$, occurring simultaneously at least in 2 esophageal measuring segments, in the absence of swallowing. Mixed liquid-gas reflux was defined as gas reflux occurring immediately before or during a liquid reflux. Gas reflux events without liquid were not considered in the analysis.

Changes in esophageal $\mathrm{pH}$ during reflux detected by impedance allowed classification of acid reflux when $\mathrm{pH}$ fell from above to below 4, and weakly acidic reflux when $\mathrm{pH}$ fell at least 1 unit but remained above 4 . Events of weakly alkaline reflux $(\mathrm{pH}$ $>7$ ) were excluded due to its rarity. For each reflux event we measured acid exposure, bolus exposure ( $5 \mathrm{~cm}$ above LES) and proximal extent (15 and $17 \mathrm{~cm}$ above LES).

Nocturnal reflux events could be isolated or occur immediately after a swallow. Post-swallow reflux was diagnosed if liquid retrograde flow started at least 5 seconds after the complete recovery of swallow induced impedance changes.

In GERD patient, the supine nocturnal period was subdivided in 1 hour intervals. Each interval was scanned for reflux episodes. The distribution of reflux events per hour during nocturnal period was analyzed from pooled data from all GERD patients. Healthy controls had little number of nocturnal reflux events to allow such characterization.

\section{Esophageal activity before and after nocturnal reflux}

Esophageal activity as detected by impedance during the 2 minute interval preceding and 2 minute interval after the start of a reflux event was classified as follows (Fig. 1): (1) aboral flow: impedance drop and recovery starting in the most proximal measuring segment (17 cm above LES) and propagating at least 2 distal segments (15 and $9 \mathrm{~cm}$ above LES), (2) reflux: another episode of reflux, (3) non-specific: unstable impedance tracing without features of antegrade or retrograde flow and (4) silent: neither flow nor impedance instability.

Clearance activity after reflux was analyzed as follows: (1) bolus clearance at $5 \mathrm{~cm}$ above LES was assessed from the impedance tracing and defined as time from $50 \%$ impedance drop to $50 \%$ impedance recovery, related to impedance baseline and
A

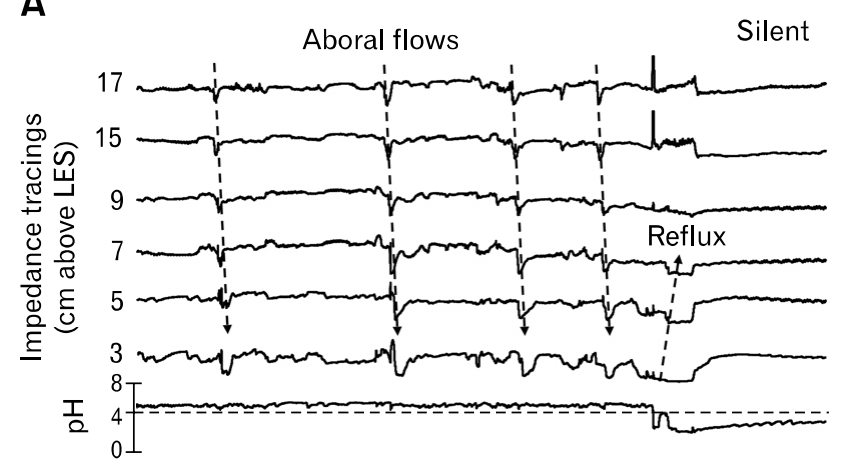

B

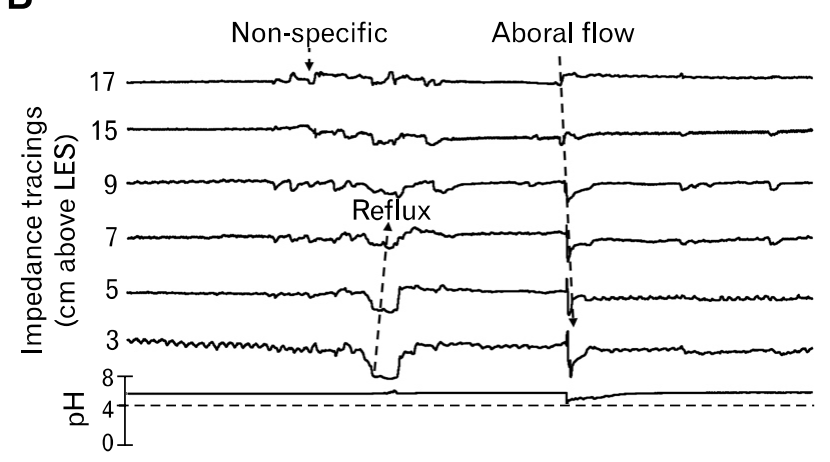

Figure 1. Esophageal activity before and after nocturnal reflux. (A) Aboral flow before and silent activity (no flow) after an episode of weakly acidic reflux. (B) Non-specific activity preceding and aboral flow following a weakly acidic reflux. LES, lower esophageal sphincter. 
(2) acid clearance was assessed from the $\mathrm{pH}$ tracing and defined as the interval between changes in $\mathrm{pH}$ from below to above 4 .

\section{Statistical Analysis}

Data which refer to healthy subjects and patients were described after per-individual analysis or when otherwise stated, whereas data regarding reflux episodes were described after pooled analysis. Quantitative variables were first tested for Gaussian distribution. Data are expressed as median and inter quartile range (25\%-75\%) or when otherwise stated. Unpaired $t$ test, Mann-Whitney test and Wilcoxon signed-rank test were employed when appropriate. Categorical variables were analyzed using Chi-square test. Differences in distribution of nocturnal reflux were evaluated using Chi-square goodness-of-fit test for total reflux analysis and Chi-square tests followed by adjusted residuals analyses for comparisons between acid and weakly acidic reflux events. A $P$-value $<0.050$ was accepted as indicating significance.

\section{Results}

\section{Characteristics of Subjects and Supine Nocturnal Period}

GERD patients and healthy subjects did not differ in regard to gender and age (Table). Chief complaint was a combination of typical and atypical reflux symptoms, followed by isolated heart- burn or acid regurgitation.

The mean interval between dinner and bedtime (start of nocturnal supine period) was $4 \mathrm{hr} 8 \mathrm{~min} \pm 1 \mathrm{hr} 33 \mathrm{~min}$ in healthy subjects and $3 \mathrm{hr} 48 \mathrm{~min} \pm 1 \mathrm{hr} 18 \mathrm{~min}$ in GERD patients $(P=$ $0.453)$. The average duration of nocturnal supine period was $8 \mathrm{hr}$ $9 \mathrm{~min} \pm 48 \mathrm{~min}$ in healthy subjects and $8 \mathrm{hr} 31 \mathrm{~min} \pm 1 \mathrm{hr} 5 \mathrm{~min}$ in GERD patients $(P=0.276)$.

\section{Prevalence and Characteristics of Nocturnal Reflux}

The median number of nocturnal reflux was $2(1-5)$ in healthy subjects and $8(4-12)$ in GERD patients $(P=0.002)$

Table. Characteristics of Patients With Gastroesophageal Reflux Disease and Healthy Volunteers

\begin{tabular}{|c|c|c|c|}
\hline & $\begin{array}{l}\text { GERD } \\
\text { patients } \\
(\mathrm{n}=76)\end{array}$ & $\begin{array}{l}\text { Healthy } \\
\text { volunteers } \\
(\mathrm{n}=11)\end{array}$ & $P$-value \\
\hline Age in years (mean $\pm \mathrm{SD})$ & $49 \pm 12$ & $46 \pm 13$ & 0.335 \\
\hline Women (n [\%]) & $47(62)$ & $5(46)$ & 0.744 \\
\hline $\begin{array}{l}\text { Symptoms (n [\%]) } \\
\text { Heartburn } \\
\text { Regurgitation } \\
\text { Atypical }^{\mathrm{a}}\end{array}$ & $\begin{array}{l}27(36) \\
15(20) \\
34(44)\end{array}$ & $\begin{array}{l}- \\
- \\
-\end{array}$ & \\
\hline
\end{tabular}

${ }^{a}$ Atypical reflux symptom combined with heartburn and/or regurgitation.

GERD, gastroesophageal reflux disease.
A

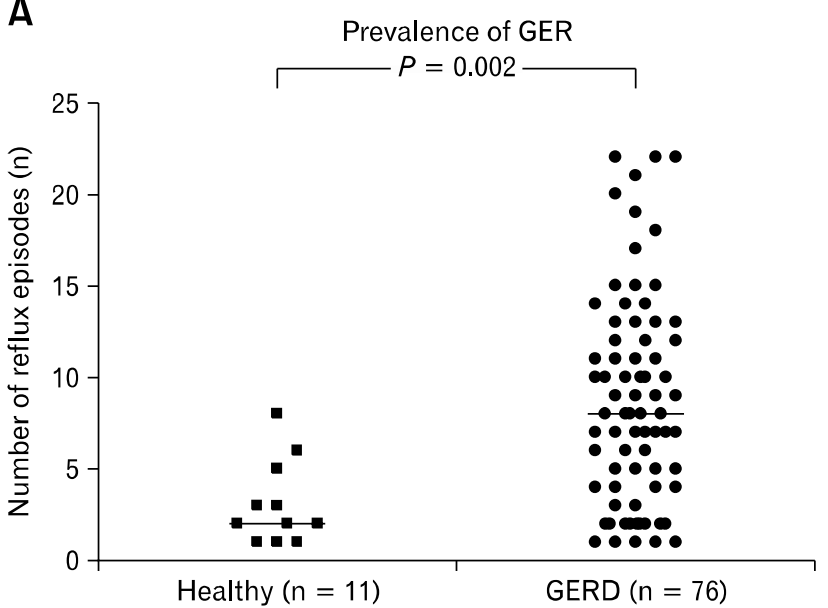

B

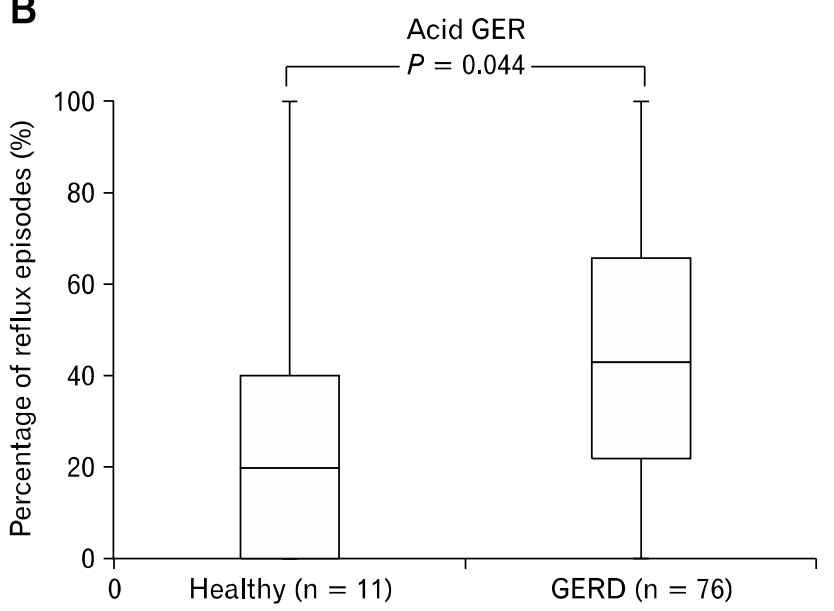

Figure 2. Prevalence and characteristics of supine nocturnal reflux in healthy subjects and patients with gastroesophageal reflux disease (GERD). (A) The total number of nocturnal reflux was significantly higher in GERD patients. (B) Healthy subjects had the majority of nocturnal events represented by weakly acidic reflux. In comparison, GERD patients had significantly more acid reflux. Central values are expressed as median. GER, gastroesophageal reflux. 
(Fig. 2A). GERD patients had significantly more reflux events per hour compared to controls $(0.9$ [0.5-1.4] vs 0.3 [0.1-0.6], $P=$ $0.003)$. At per-individual analysis, healthy subjects had a median (interquartile range $25 \%-75 \%)$ of $20 \%(0 \%-40 \%)$ of acid and $80 \%(60 \%-100 \%)$ of weakly acidic reflux. In contrast, GERD patients had $43 \%(22 \%-65 \%)$ of acid and $57 \%$ (35\%-78\%) of weakly acidic reflux $(P=0.044)$ (Fig. 2B). Thus, GERD patients had a lower proportion of weakly acidic reflux compared to controls. Most nocturnal reflux was pure liquid both in controls (100\% [75\%-100\%]) and in patients (76\% [44\%-100\%]). Taking all subjects, $80 \%$ of reflux events were pure liquid.

A similar proportion of nocturnal reflux reached $15 \mathrm{~cm}$ above the LES in GERD patients and controls (33\% [20\%-50\%] vs $20 \%$ [0\%-50\%], $P=0.671)$. Nocturnal reflux reached the most proximal impedance segment (17 $\mathrm{cm}$ above LES) more often in GERD patients than in controls $(6 \%$ [0\%-29\%] vs $0 \%$ [0\%0\%], $P=0.047)$.

In GERD patients, acid reflux reached more often the proximal esophagus ( $15 \mathrm{~cm}$ above the LES) compared to weakly acidic reflux (50\% [17\%-75\%) vs $17 \%$ [0\%-50\%], $P<0.001)$. The majority of acid reflux (98\%) and weakly acidic reflux (87\%) occurred with a gastric $\mathrm{pH}<4$, measured in the fundus-corpus approximately $5-7 \mathrm{~cm}$ distal to LES.

\section{Distribution of Nocturnal Reflux}

We examined a total of 600 reflux events that occurred in the first 8 hours of the nocturnal supine period of GERD patients.
Reflux was significantly more frequent during the first hour and less numerous in the fifth and sixth hours of the nocturnal period $(P<0.001)$ (Fig. 3A). During the first 2 hours, acid reflux was significantly more frequent than weakly acidic reflux, which became predominant in the last 3 hours $(P<0.001)$ (Fig. 3B).

Patients with normal total acid exposure had mostly weakly acidic reflux during the whole nocturnal supine period, whereas patients with abnormal acid exposure in upright position had predominance of acid events in the first 2 hours. Patients with bi-positional increased acid exposure had predominant acid reflux during the first 6 hours, changing to weakly acidic reflux in the last 2 hours of the nocturnal period (Fig. 4).

\section{Esophageal Activity Preceding Nocturnal Reflux}

The esophageal activity detected by impedance on 2 minute interval preceding nocturnal reflux was similar between acid and weakly acidic events. In the pooled analysis, the majority of nocturnal reflux was preceded by episodes of esophageal aboral flow both in healthy subjects (78\%) and GERD patients (74\%). A silent interval was observed in $14 \%$ and $11 \%$ of the respective cases. A second reflux episode occurred in $3 \%$ and $6 \%$ of cases, whereas non-specific changes occurred in $5 \%$ and $9 \%$ of cases respectively.

\section{Esophageal Activity After Nocturnal Reflux}

Median bolus clearance in the pooled analysis of all reflux was similar in GERD patients and controls (16 [13-19] vs 16
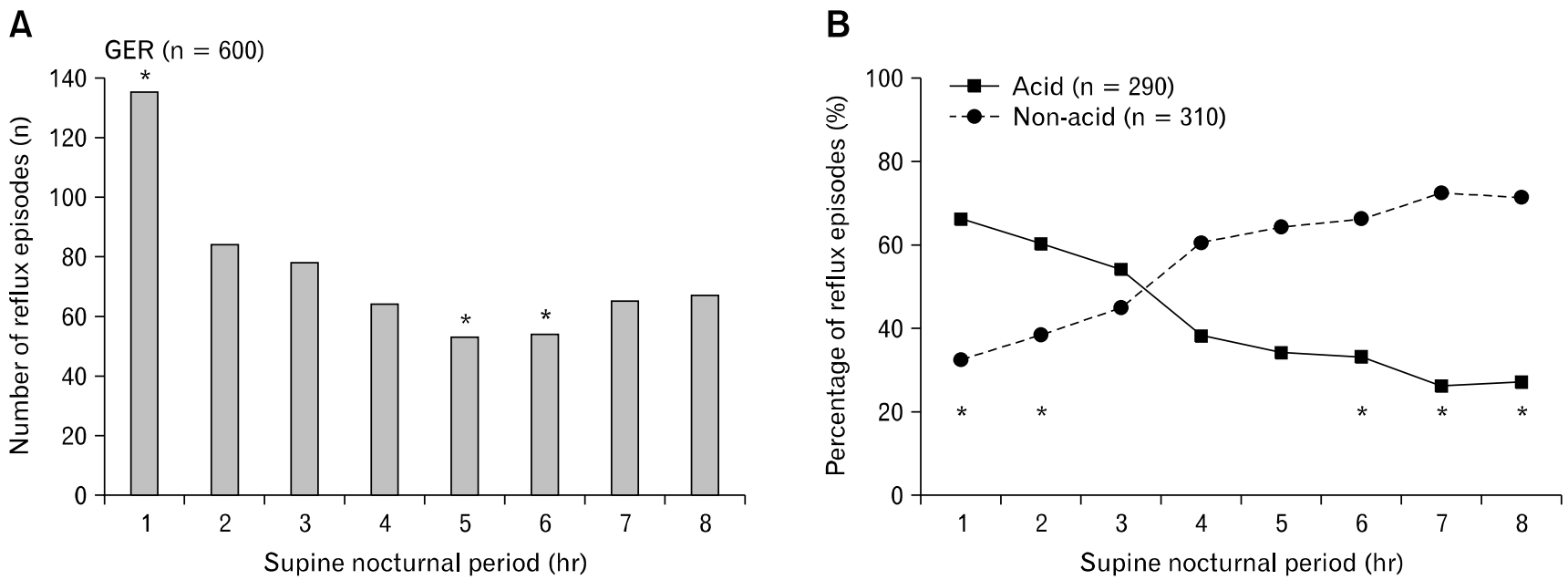

Figure 3. Distribution of nocturnal reflux in patients with gastroesophageal reflux disease (GERD). (A) Reflux events in 8 hours of the supine nocturnal period. Reflux was significantly more frequent in the first hour and significantly less numerous in the fifth and sixth hours $(* P<0.001)$. (B) Distribution of weakly acidic and acid reflux in GERD patients. Acid events predominated in the first 2 hours whereas weakly acidic reflux became more common in the last 3 hours of the nocturnal period $\left({ }^{*} P<0.001\right)$. GER, gastroesophageal reflux. 
A Normal AE

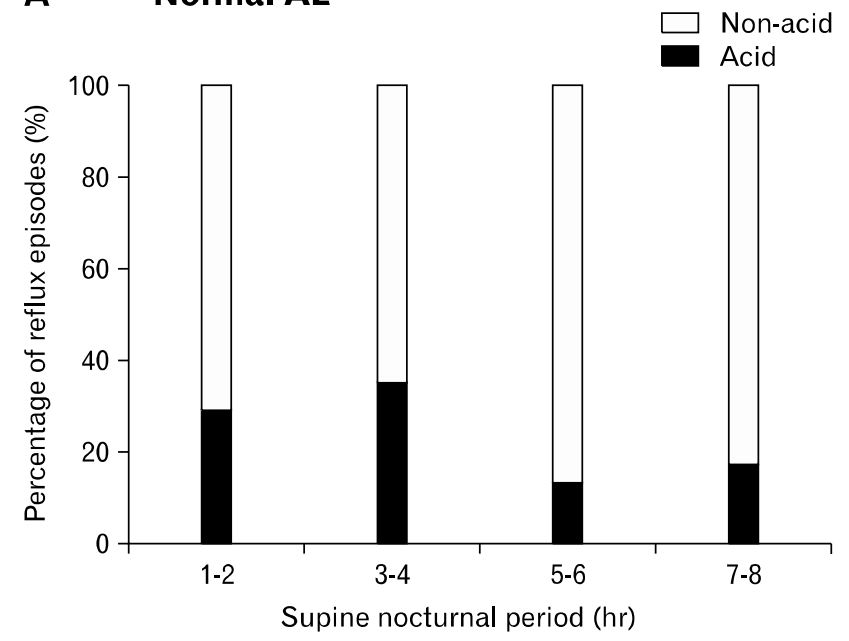

C Bi-positional increased AE

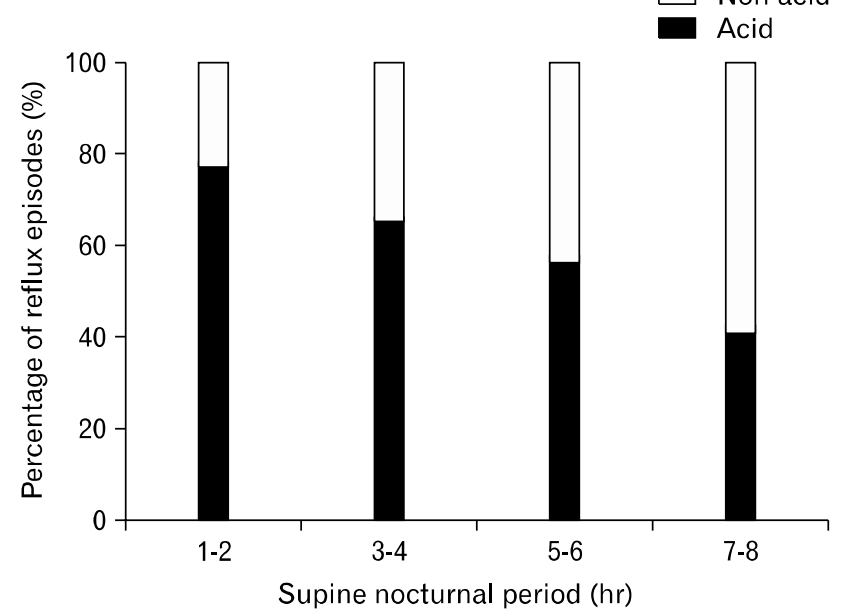

[12-19] sec, $P=0.793)$. In GERD patients, acid reflux had longer bolus clearance compared to weakly acidic reflux (18 [12-25] vs $16[11-20] \mathrm{sec}, P<0.001)$. Acid clearance lasted significantly longer than bolus clearance in both patients (44 [12-133] vs 18 [12-25] sec, $P<0.001)$ and controls (37 $[12-88]$ vs 10 [7-14] sec, $P<0.005)$. In patients with increased nocturnal acid exposure, such differences were much more pronounced (68 [21-182] vs 17 [12-26] sec, $P<0.001$ ).

The esophageal activity detected by impedance during the 2-minute period after acid reflux was compared between reflux events with short $(<102 \mathrm{sec})$ and prolonged $(>102 \mathrm{sec})$ acid clearance (95th percentile of acid clearance in controls $=102$ sec). Bolus clearance did not differ between events with short and prolonged acid clearance (17 [11-22] vs 18 [12-27] sec, $P=$

\section{B Upright increased AE}

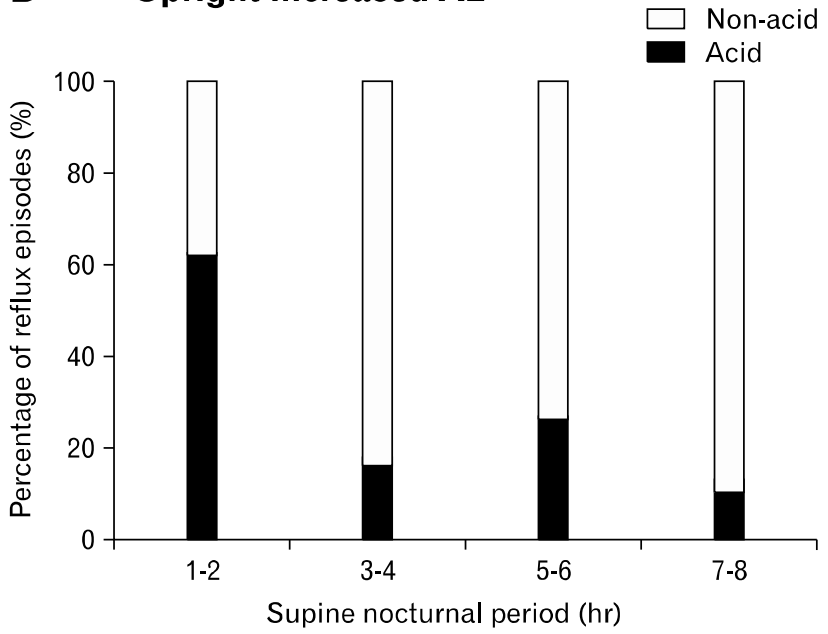

Figure 4. Distribution of nocturnal reflux in patients with gastroesophageal reflux disease with different degrees of acid exposure (AE). (A) Patients with normal AE had mostly weakly acidic reflux during the whole nocturnal supine period. (B) Those with upright increased AE had predominance of acid events in the first 2 supine hours. (C) Patients with bi-positional increased $\mathrm{AE}$ had predominant acid reflux during the first 6 hours and weakly acidic reflux in the last 2 hours.

0.201). However, episodes of aboral flow were significantly less frequent following reflux events with prolonged acid clearance (59\% vs $79 \%, P<0.010)$.

Esophageal acid clearance changed along the supine nocturnal period (Fig. 5). Acid clearance was significantly longer in the interval between the third and fifth hour and this was not due to differences in bolus clearance but rather associated with significantly less post-reflux aboral activity.

\section{Discussion}

We hypothesized that by using impedance-pH monitoring, it would be possible to assess spontaneous or swallow induced esophageal activity preceding nocturnal reflux, as well as the 
A

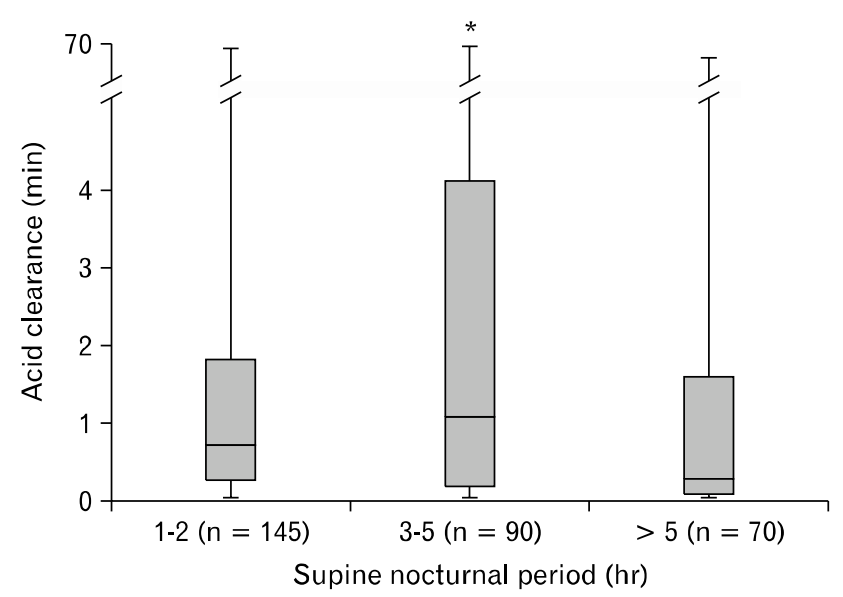

B $\square$ Aboral flow

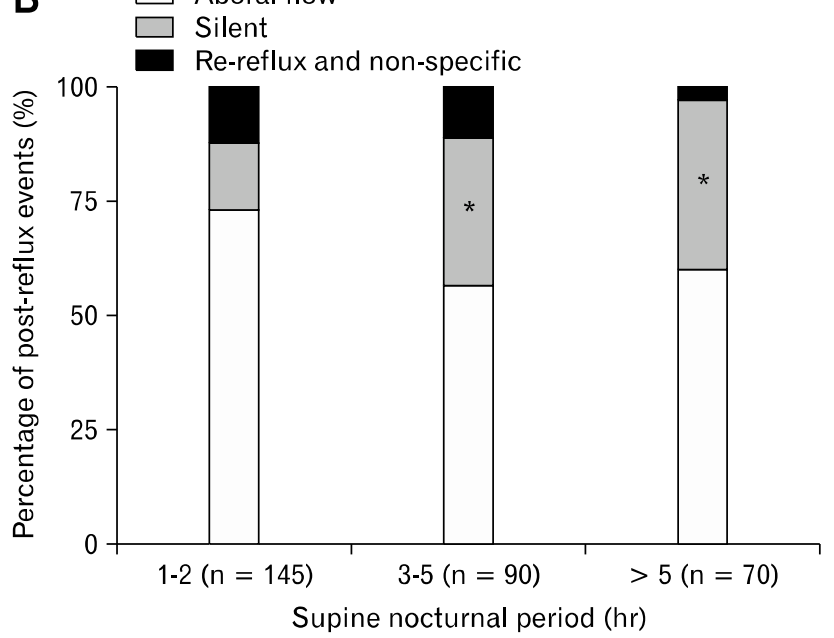

Figure 5. Distribution of nocturnal acid clearance and corresponding patterns of post-reflux esophageal activity. (A) Acid clearance was significantly longer for acid reflux identified in the interval between the third and fifth hour after lying down. ${ }^{*} P<0.050$ vs $1-2$ and $>5$. (B) Silent esophageal activity seen at impedance after acid reflux was significantly more frequent starting from the third hour after lying down. ${ }^{*} P<0.050$ vs $1-2$.

prevalence and characteristics of reflux events, and the patterns of volume and chemical clearance after nocturnal reflux. For this purpose, we carefully re-assessed impedance-pH tracings from healthy subjects and GERD patients off PPI.

Our main findings were: (1) weakly acidic reflux represented most of nocturnal reflux events in healthy subjects and half of episodes in GERD patients; (2) in both groups, nocturnal reflux was composed mainly by pure liquid, but reached the proximal esophagus more often in patients; (3) total nocturnal reflux was more numerous in the first hour of the supine period, with predominance of acid reflux earlier and weakly acidic reflux later in the night; (4) pre-reflux esophageal activity detected by impedance was characterized mainly by aboral flows; (5) post-reflux activity determining bolus clearance time was similar between controls and patients or weakly acidic and acid reflux; and (6) in GERD patients, prolonged chemical clearance after acid reflux was associated with less esophageal activity seen at impedance, particularly in the middle of the night.

Weakly acidic reflux is believed to occur mainly after meals, when the gastric environment is buffered by food. In GERD patients under acid-suppressive therapy, weakly acid reflux replaces acid events and follows the conventional distribution of reflux. $^{25,26}$ Although nocturnal weakly acidic reflux has been described as an uncommon event, few studies have formally addressed this issue. In the present study, weakly acidic reflux represented the majority of nocturnal reflux events identified in healthy subjects and half of reflux episodes in GERD patients.
Recent studies in healthy subjects have shown that weakly acid reflux corresponds to approximately $50 \%$ of all nocturnal reflux. ${ }^{16,17,27}$ Orr et $\mathrm{al}^{15}$ reported lower rates of nocturnal weakly acidic reflux in a small group of GERD patients off PPI. In that study, the authors attempted to induce more nocturnal acid reflux by employing a late-evening provocative meal. GERD patients consuming a late-evening meal were demonstrated to have significantly greater supine acid reflux compared when they ate earlier. ${ }^{28}$ The fact that our patients had dinner 4 hours before bedtime on average can explain such differences and support a clinical benefit in avoiding late-evening meals.

Nocturnal reflux was composed mainly of liquid in both patients and controls. This observation is in agreement with other studies in healthy subjects ${ }^{16,17}$ and GERD patients. ${ }^{25}$ It is known that reflux composition varies if patient is lying down or standing. In supine position, liquid reflux is favored by movement of the gastric bubble far from the cardia. ${ }^{29}$ Supine position may also influence the frequency by which reflux reaches the proximal esophagus. We found that GERD patients had more reflux episodes reaching the very proximal esophagus $(17 \mathrm{~cm}$ above the LES) than controls, particularly for acid reflux. In contrast to nocturnal reflux, a study using impedance-pH monitoring found no difference comparing proximal extension of diurnal acid and weakly acidic reflux. ${ }^{16}$ It must be mentioned that the occurrence of acid reflux reaching the proximal esophagus during the supine nocturnal period may be a contributing factor for extra-esophageal manifestations in GERD patients. ${ }^{30,31}$ The employment of im- 
pedance-pH monitoring might be useful in recommending elevated head in GERD patients with proximal reflux.

Nocturnal acid reflux has been described as an early event by studies employing standard $\mathrm{pH}$ monitoring. ${ }^{32,33} \mathrm{By}$ using impedance-pH monitoring, we not only confirmed this observation but also showed that weakly acid reflux is increasingly prevalent later in the night. The mechanisms and clinical relevance of this finding are unclear. Marshall et $\mathrm{al}^{34}$ described that GERD patients had less acidified bile reflux occurring with increased frequency throughout the night, particularly in the presence of reflux esophagitis. Studies on circadian gastric secretion have shown that both gastrin levels and acid output increases significantly late in the evening and decreases early in the morning, when high $\mathrm{pH}$ values are identified in the gastric corpus. ${ }^{35-38}$ Such pattern of nocturnal gastric secretion partially explains the predominance of weakly acidic reflux in the later part of the night.

In our study, impedance analyses opened the possibility to identify different patterns of esophageal activity associated with nocturnal reflux. In the 2 minute interval preceding reflux, aboral flow was the most common observed pattern of esophageal activity. During the sleep, sparse aboral flows were likely to represent saliva deglutition drive by esophageal peristalsis. ${ }^{19}$ Based on the fact that deglutition depends on arousals, our findings are in accordance with the general belief that arousals play an important role in the pathophysiology of nocturnal reflux. ${ }^{6}$ Therefore, pre-reflux aboral flows seen at impedance might be a marker of arousals, which could allow TLESRs, the major mechanism involved in nocturnal reflux. ${ }^{11,12}$ Recent studies using actigraphy technology have indicated that nocturnal reflux occurs primarily after an awakening episode. ${ }^{21}$ A clinical implication of these findings includes a potential benefit of TLERs inhibitors, such as baclofen. ${ }^{39}$

The ability of esophagus to clear reflux bolus was similar between controls and patients. This was also observed on comparing acid with weakly acidic reflux. Moreover, GERD patients had longer bolus clearance after acid reflux compared to weakly acidic reflux, which might be explained by increased reflux volume and delayed esophageal response after acid reflux. ${ }^{40}$ From studies using conventional $\mathrm{pH}$ monitoring, it has been demonstrated that GERD patients with severe ineffective esophageal motility have higher probability of prolonged clearance after supine acid reflux. ${ }^{41}$ In our study, the absence of data regarding esophageal body motility precluded the correlation between motor performance and bolus clearance of nocturnal reflux. Neverthe- less, we were able to assess the effect of post-reflux esophageal activity seen at impedance on the process of chemical clearance after nocturnal acid reflux. In agreement with the 2-step process described by Helm et al, ${ }^{42}$ in which chemical clearance was initiated by esophageal peristaltic response and completed by saliva deglutition, we found an association between less aboral flow, interpreted as decreased saliva transport, and more prolonged chemical clearance in GERD patients. This phenomenon was more evident in the intermediate hours of the nocturnal period. Conversely, most of acid reflux events identified in the first 2 hours of the period had aboral flows during the process of $\mathrm{pH}$ recovery, suggesting that either patients were awake or the vigilance system of the esophagus to acid reflux varies in different sleep stages. ${ }^{43-45}$ In support of the first hypothesis, a recent study using actigraphy to monitor physical activity during the supine nocturnal period has shown that most nocturnal reflux events occur during recumbent-awake and not the recumbent-asleep period. ${ }^{20}$

The finding that nocturnal weakly acidic reflux was more frequent than expected raises a question about its clinical relevance. Some evidences point out an association between this type of reflux and both symptoms and esophageal mucosa damage. The presence of bile components in nocturnal weakly acidic reflux is a fact. ${ }^{34,46,47}$ From our laboratory, an experimental study showed that weakly acidic solutions containing physiological amounts of bile acids and pepsin could significantly increase the esophageal mucosa permeability. ${ }^{48}$ Nocturnal sensitization of esophageal mucosa after exposure to damaging weakly acidic reflux might favor the occurrence of diurnal symptoms, including sour or bitter taste in the mouth. ${ }^{49}$ A clinical role for weakly acidic reflux has already been suggested by the association between this type of reflux and both typical and atypical diurnal GERD symptoms. ${ }^{26,47,50-52}$ Finally, the variability in reflux composition, including weakly acidic events, might explain the difference in severity of esophageal lesions in patients with similar amounts of acid reflux. $^{53}$

In conclusion, we reappraised nocturnal reflux using impedance-pH monitoring in healthy subjects and GERD patients. Our main findings were the high predominance of weakly acidic reflux during the night in both controls and patients, the characteristics of nocturnal reflux, including predominant liquid composition and higher proximal extent in GERD patients, and a peculiar time distribution of weakly acidic reflux as a late phenomenon, pointing to the need of further studies to address the clinical relevance of nocturnal weakly acidic reflux. We also demonstrated that impedance monitoring could assess patterns of 
esophageal activity associated with nocturnal reflux, precluding the need for a sleep laboratory. Accordingly, impedance-pH monitoring might be useful to evaluate pre-reflux esophageal activity and post-reflux poor esophageal activity associated with prolonged acid clearance. Further studies with this methodology are needed to clarify the relation of weakly acidic reflux with nocturnal symptoms and possible differences between patients with erosive and non-erosive reflux disease.

\section{References}

1. Dickman R, Green C, Fass SS, et al. Relationships between sleep quality and $\mathrm{pH}$ monitoring findings in persons with gastroesophageal reflux disease. J Clin Sleep Med 2007;3:505-513.

2. Dubois RW, Aguilar D, Fass R, et al. Consequences of frequent nocturnal gastro-oesophageal reflux disease among employed adults: symptom severity, quality of life and work productivity. Aliment Pharmacol Ther 2007;25:487-500.

3. Farup C, Kleinman L, Sloan S, et al. The impact of nocturnal symptoms associated with gastroesophageal reflux disease on health-related quality of life. Arch Intern Med 2001;161:45-52.

4. Fornari F, Madalosso CA, Callegari-Jacques SM, Gurski RR. Heartburn during sleep: a clinical marker of gastro-oesophageal reflux disease in morbidly obese patients. Neurogastroenterol Motil 2009;21:136-142.

5. Jung HK, Choung RS, Talley NJ. Gastroesophageal reflux disease and sleep disorders: evidence for a causal link and therapeutic implications. J Neurogastroenterol Motil 2010;16:22-29.

6. Orr WC, Heading R, Johnson LF, Kryger M. Review article: sleep and its relationship to gastro-oesophageal reflux. Aliment Pharmacol Ther 2004;20(suppl 9):39-46.

7. Schey R, Dickman R, Parthasarathy S, et al. Sleep deprivation is hyperalgesic in patients with gastroesophageal reflux disease. Gastroenterology 2007;133:1787-1795.

8. Shaker R, Castell DO, Schoenfeld PS, Spechler SJ. Nighttime heartburn is an under-appreciated clinical problem that impacts sleep and daytime function: the results of a Gallup survey conducted on behalf of the American gastroenterological association. Am J Gastroenterol 2003;98:1487-1493.

9. Orr WC, Allen ML, Robinson M. The pattern of nocturnal and diurnal esophageal acid exposure in the pathogenesis of erosive mucosal damage. Am J Gastroenterol 1994;89:509-512.

10. Lagergren J, Bergström R, Lindgren A, Nyrén O. Symptomatic gastroesophageal reflux as a risk factor for esophageal adenocarcinoma. N Engl J Med 1999;340:825-831.

11. Freidin N, Fisher MJ, Taylor W, et al. Sleep and nocturnal acid reflux in normal subjects and patients with reflux oesophagitis. Gut 1991;32:1275-1279.

12. Dent J, Dodds WJ, Friedman RH, et al. Mechanism of gastroesophageal reflux in recumbent asymptomatic human subjects. J Clin Invest 1980;65:256-267.

13. van Herwaarden MA, Samsom M, Smout AJ. Excess gastroesophageal reflux in patients with hiatus hernia is caused by mecha- nisms other than transient LES relaxations. Gastroenterology 2000; 119:1439-1446.

14. Mainie I, Tutuian R, Shay S, et al. Acid and non-acid reflux in patients with persistent symptoms despite acid suppressive therapy: a multicentre study using combined ambulatory impedance-pH monitoring. Gut 2006;55:1398-1402.

15. Orr WC, Craddock A, Goodrich S. Acidic and non-acidic reflux during sleep under conditions of powerful acid suppression. Chest 2007;131:460-465.

16. Shay S, Tutuian R, Sifrim D, et al. Twenty-four hour ambulatory simultaneous impedance and $\mathrm{pH}$ monitoring: a multicenter report of normal values from 60 healthy volunteers. Am J Gastroenterol 2004;99:1037-1043

17. Zerbib F, des Varannes SB, Roman S, et al. Normal values and day-to-day variability of 24-h ambulatory oesophageal impedance$\mathrm{pH}$ monitoring in a Belgian-French cohort of healthy subjects. Aliment Pharmacol Ther 2005;22:1011-1021.

18. Zerbib F, Roman S, Ropert A, et al. Esophageal pH-impedance monitoring and symptom analysis in GERD: a study in patients off and on therapy. Am J Gastroenterol 2006;101:1956-1963.

19. Holloway RH. Esophageal body motor response to reflux events: secondary peristalsis. Am J Med 2000;108(suppl 4a):20S-26S.

20. Allen L, Poh CH, Gasiorowska A, et al. Increased oesophageal acid exposure at the beginning of the recumbent period is primarily a recumbent-awake phenomenon. Aliment Pharmacol Ther 2010;32: 787-794.

21. Poh $\mathrm{CH}$, Allen L, Gasiorowska A, et al. Conscious awakenings are commonly associated with acid reflux events in patients with gastroesophageal reflux disease. Clin Gastroenterol Hepatol 2010;8:851857.

22. Orr WC, Johnson LF, Robinson MG. Effect of sleep on swallowing, esophageal peristalsis, and acid clearance. Gastroenterology 1984; 86(5 Pt 1):814-819.

23. Orr WC, Robinson MG, Johnson LF. The effect of esophageal acid volume on arousals from sleep and acid clearance. Chest 1991; 99:351-354.

24. Johnson LF, Demeester TR. Twenty-four-hour pH monitoring of the distal esophagus. A quantitative measure of gastroesophageal reflux. Am J Gastroenterol 1974;62:325-332.

25. Sifrim D, Holloway R, Silny J, et al. Acid, nonacid, and gas reflux in patients with gastroesophageal reflux disease during ambulatory 24-hour pH-impedance recordings. Gastroenterology 2001;120: 1588-1598.

26. Vela MF, Camacho-Lobato L, Srinivasan R, Tutuian R, Katz PO, Castell DO. Simultaneous intraesophageal impedance and $\mathrm{pH}$ measurement of acid and nonacid gastroesophageal reflux: effect of omeprazole. Gastroenterology 2001;120:1599-1606.

27. Zentilin $\mathrm{P}$, Iiritano E, Dulbecco $\mathrm{P}$, et al. Normal values of 24-h ambulatory intraluminal impedance combined with $\mathrm{pH}$-metry in subjects eating a Mediterranean diet. Dig Liver Dis 2006;38:226-232.

28. Piesman M, Hwang I, Maydonovitch C, Wong RK. Nocturnal reflux episodes following the administration of a standardized meal. Does timing natter? Am J Gastroenterol 2007;102:2128-2134.

29. Shay SS, Conwell DL, Mehindru V, Hertz B. The effect of posture on gastroesophageal reflux event frequency and composition during fasting. Am J Gastroenterol 1996;91:54-60. 
30. Farrokhi F, Vaezi MF. Extra-esophageal manifestations of gastroesophageal reflux. Oral Dis 2007;13:349-359.

31. Vakil N, van Zanten SV, Kahrilas P, Dent J, Jones R; Global Consensus Group. The Montreal definition and classification of gastroesophageal reflux disease: a global evidence-based consensus. Am J Gastroenterol 2006;101:1900-1920.

32. Dickman R, Parthasarathy S, Malagon IB, et al. Comparisons of the distribution of oesophageal acid exposure throughout the sleep period among the different gastro-oesophageal reflux disease groups. Aliment Pharmacol Ther 2007;26:41-48.

33. Hila A, Castell DO. Nighttime reflux is primarily an early event. J Clin Gastroenterol 2005;39:579-583.

34. Marshall RE, Anggiansah A, Owen WA, Owen WJ. The temporal relationship between oesophageal bile reflux and $\mathrm{pH}$ in gastro-oesophageal reflux disease. Eur J Gastroenterol Hepatol 1998; 10:385-392.

35. Bianco A, Cagossi M, Piraccini R, Castrucci G, Greco AV. The nightly spontaneous alkalinization of the stomach. Riv Eur Sci Med Farmacol 1993;15:17-27.

36. Iraki L, Bogdan A, Hakkou F, Amrani N, Abkari A, Touitou Y. Ramadan diet restrictions modify the circadian time structure in humans. A study on plasma gastrin, insulin, glucose, and calcium and on gastric pH. J Clin Endocrinol Metab 1997;82:1261-1273.

37. Moore JG. Circadian dynamics of gastric acid secretion and pharmacodynamics of H2 receptor blockade. Ann N Y Acad Sci 1991; 618:150-158.

38. Saitoh T, Watanabe $Y$, Kubo Y, et al. Intragastric acidity and circadian rhythm. Biomed Pharmacother 2001;55(suppl 1):138s-141s.

39. Tsoukali E, Sifrim D. The role of weakly acidic reflux in proton pump inhibitor failure, has dust settled? J Neurogastroenterol Motil 2010;16:258-264.

40. Woodland P, Sifrim D. The refluxate: the impact of its magnitude, composition and distribution. Best Pract Res Clin Gastroenterol 2010;24:861-871.

41. Fornari F, Blondeau K, Durand L, et al. Relevance of mild ineffective oesophageal motility (IOM) and potential pharmacological reversibility of severe IOM in patients with gastro-oesophageal reflux disease. Aliment Pharmacol Ther 2007;26:1345-1354.

42. Helm JF, Dodds WJ, Pelc LR, Palmer DW, Hogan WJ, Teeter
BC. Effect of esophageal emptying and saliva on clearance of acid from the esophagus. N Engl J Med 1984;310:284-288.

43. Castiglione F, Emde C, Armstrong D, et al. Nocturnal oesophageal motor activity is dependent on sleep stage. Gut 1993;34:1653-1659.

44. Dickman R, Shapiro M, Malagon IB, Powers J, Fass R. Assessment of 24-h oesophageal $\mathrm{pH}$ monitoring should be divided to awake and asleep rather than upright and supine time periods. Neurogastroenterol Motil 2007;19:709-715.

45. Orr WC, Johnson LF. Responses to different levels of esophageal acidification during waking and sleep. Dig Dis Sci 1998;43:241-245.

46. Koek GH, Tack J, Sifrim D, Lerut T, Janssens J. The role of acid and duodenal gastroesophageal reflux in symptomatic GERD. Am J Gastroenterol 2001;96:2033-2040.

47. Tack J, Koek G, Demedts I, Sifrim D, Janssens J. Gastroesophageal reflux disease poorly responsive to single-dose proton pump inhibitors in patients without Barrett's esophagus: acid reflux, bile reflux, or both? Am J Gastroenterol 2004;99:981-988.

48. FarréR, van Malenstein H, De Vos R, et al. Short exposure of oesophageal mucosa to bile acids, both in acidic and weakly acidic conditions, can impair mucosal integrity and provoke dilated intercellular spaces. Gut 2008;57:1366-1374.

49. Poh CH, Allen L, Malagon I, et al. Riser's reflux - an eye-opening experience. Neurogastroenterol Motil 2010;22:387-394.

50. Blondeau K, Dupont LJ, Mertens V, Tack J, Sifrim D. Improved diagnosis of gastro-oesophageal reflux in patients with unexplained chronic cough. Aliment Pharmacol Ther 2007;25:723-732.

51. Koek GH, Sifrim D, Lerut T, Janssens J, Tack J. Effect of the $\mathrm{GABA}(\mathrm{B})$ agonist baclofen in patients with symptoms and duodeno-gastro-oesophageal reflux refractory to proton pump inhibitors. Gut 2003;52:1397-1402.

52. Sifrim D, Dupont L, Blondeau K, Zhang X, Tack J, Janssens J. Weakly acidic reflux in patients with chronic unexplained cough during 24 hour pressure, $\mathrm{pH}$, and impedance monitoring. Gut 2005;54:449-454.

53. Fiorucci S, Distrutti E, Di Matteo F, et al. Circadian variations in gastric acid and pepsin secretion and intragastric bile acid in patients with reflux esophagitis and in healthy controls. Am J Gastroenterol 1995;90:270-276. 